\title{
Influence of Organizational Culture, Supervisor Behavior and HRM Practices on Employee Turnover Intentions: Study of NGOs Sector of Sindh, Pakistan
}

\author{
* Tauqeer Hussain Hakro, Lecturer \\ ** Khalid Hussain Abbasi, Assistant Professor (Corresponding Author) \\ *** Hakim Ali Mahesar, Associate Professor
}

\begin{abstract}
The primary objective of this study was to investigate the influence of organizational culture, supervisor behavior, and HRM practices over the employee turnover intentions of the NGOs sector in Sindh, Pakistan. A questionnaire survey, adopted from prior studies for data collection was used to carry out current research. The questionnaire was based on close-ended questions, having a sevenpoint Likert-type scale. The convenient sampling (an item of non-probability sampling) was used to collect data. A total of 180 questionnaires were distributed among employees of the NGOs sector, out of which 121 questionnaires were considered fit for data analysis and further interpretations. Initially, the data was processed in SPSS version 22.0 for analyzing descriptive statistics, whereas, the model was tested in SEM Smart-PLS. The organizational culture, supervisor behavior, and HRM practices were the significant predictors to reduce employee turnover intentions. While HRM practices and supervisor behavior contribute to decreasing employee turnover intentions. Furthermore, this study explained the interconnection of various factors such as, organizational culture, supervisor behavior, and HRM practices that cause employee turnover intentions, which were realized by actual employee turnover. The investigation provided explanations about why NGO employees intend to quit. Referring to empirical findings of current research, it is highly likely that NGOs might be able to reduce employee turnover. This research addressed specific circumstances of NGOs that cause high employee turnover, particularly in Sindh, which may be generalized at the country level.
\end{abstract}

Keywords: Organizational Culture, HRM Practices, Supervisor Behavior, Employee Turnover Intentions, and Employee Turnover

\section{Introduction}

Employee turnover intentions have attracted the attention of researchers and corporate officers of HR in the last few decades (Price, 2001). Researchers and corporate officers are interested to know about reasons that why employee turnover intentions occur at the workplace (Mobley et al., 1979). Employee turnover intentions hurt employee performance as well as reduces employee morale to work more for the organization (Griffeth et al., 2000). It prevents employees not to keep constructive thinking about the organization. Almost all employees engage themselves in search of alternate opportunities available in the market (Hom, et al., 2012). Turnover is realized when employees leave the organization. It is worst for an organization when its employees are frequently leaving their jobs and finding opportunities in a similar type of organization and even joining similar kinds of positions (Vandanberg \& Nelson, 1999: Salleh et al, 2020).

The most common causes for employee turnover intentions are organizational culture, supervisor behavior, and HRM practices. Which are directly related to employee turnover intentions (Chen, 2001). Especially, when these are not good at work such as employees are not treated fairly at work, there is no appreciation and encouragement in the organizational culture, the supervisor is not supportive and best guide for employees, employees are not recruited and selected in a rightful way they are not trained as per their job needs, compensations are not good compared to other similar

\footnotetext{
* Department of Commerce, University of Sindh, Mirpurkhas Campus Email: tauqeer.hakro@usindh.edu.pk

** Department of Commerce, University of Sindh, Laar Campus, Badin Email: khalid.abbasi@ usindh.edu.pk

*** Institute of Commerce, University of Sindh, Alama I.I Qazi Campus, Jamshoro

Email: hakim.mahesar@usindh.edu.pk
} 
organizations, performance is not evaluated based on merit, increments and promotions are not awarded based on performance. Ultimately employees get depressed at work and their performance declines, they bring ideas in their minds to search for another opportunity in the market that will pay them well rather than stay on the present job in the current organization. To stay on the present job in the current organization would be a great sacrifice that is unbearable for those who can easily find opportunities in the market (Abagelan \& Tullu, 2020).

\section{Research Gap}

There is a lack of empirical study and literature review on the topic of employee turnover intentions, especially in the context of Pakistan. Only a few relevant studies are available, which were undertaken in the banking sector of Sindh and Punjab (Rizwan et al., 2014; Mahesar, 2015). Since there is no research carried out on the NGOs sector of Sindh, Pakistan. It was suggested that further research should be undertaken on the topic of employee turnover intentions in the private sector of Pakistan (Jhatial et al., 2012). This study is about employee turnover intentions in the NGOs sector of Sindh, Pakistan. This study will help to bridge the gap by providing solutions related to employee turnover intentions specifically for the NGOs sector of Sindh and generally for Pakistan.

\section{Objectives of the study}

1. Identify the impact of organizational culture on employee turnover intentions.

2. Identify the impact of supervisor behavior on employee turnover intentions.

3. Identify the impact of HRM practices on employee turnover intentions.

4. Identify the impact of organizational culture on HRM practices.

5. Identify the impact of supervisor behavior on HRM practices.

\section{Literature review}

\section{Organizational culture}

Organizational culture is the set of values, beliefs and norms shared and practiced by organizational members within the organization to identify organizational goals and achieve them with the efforts of employees and management (Hofstede, 2011). Shared beliefs and values are exercised within the organizations which form behavior patterns of employees. Employees adapt organizational culture to identify and achieve set goals of the organization (House, R.J. et al., 2004). A supportive organizational culture is indeed a motivational factor that prevails in the organization and encourages employees to achieve goals by contributing valuable inputs in their jobs and remain attached with the organization for a long time (Inglehart, 1997). Organizational culture is the cooperative process that divides employees into many groups within organizations so that they adjust with other group members and working with them to achieve organizational goals (Hofstede, 2011: Sabuhari, 2020).

\section{Supervisor behavior}

At present management of organizations needs efficient supervisors who influence employees to achieve organizational goals (Gilbreath, 2005). A supervisor who behaves employees well wins trust and compels them to accomplish organizational goals. Almost all organizations face turnover problems nowadays that caused by numerous factors, for instance, unsupportive supervisor behavior, bad working environment, job dissatisfaction, compensation disparity in the labor market, and many more (Hoobler, 2006). Despite the factors connected with internal and external sources of job dissatisfaction. Resultantly to run the business triumphantly on the job satisfaction principle which is the way to reduce employee turnover (Jansson, 2006). Employees put all their efforts possible in performing good jobs which are hardly perceived and in consequence increases job dissatisfaction. Critical organizational decisions with few or no employee involvement, this attitude scatters rather than holds employees with the organization, (Karimi et al., 2011: Sardar \& Mahdi, 2020).

\section{HRM Practices}

Nowadays, the world is growing to be more competitive and uneven. Organizations are trying to gain a competitive advantage at every cost and moving towards more innovative sources of HRM practices, (Sun \& Law, 2007). HRM practices have been explained in numerous ways. HRM practices as a system that fascinates, improves, inspires, and keep employees in the organization for a long time to make sure the effective carrying out the operations of the organization (Wood \& Wall, 2002; Ahmed et al, 2020; Da Silva et al, 2020 and Amin \& Rubal, 2020).

Recruitment and selection can be defined as the process of inviting applications and creating a pool of candidates for vacant jobs. It is not a simple process of selection but it needs decision making and comprehensive planning so that suitable candidates to be appointed on suitable positions especially 
whose skills and qualification meet with the job and having enough talent to work for the organization (Mahesar, 2015). Organizations that are competing with each other design new and transparent ways to attract people to work for the organizations. Thus, the candidates who have the potential to be appointed on various jobs with the right level of skills and competencies to run the organizational routine activities. Selected candidates are provided orientation with existing staff members, overall departments of the organization, what the organization wants to be in the future with what strategic planning, and what the organization expects from employees to do at work (Price, 1986).

Training can be defined as teaching new employees basic skills of the job or developing the skills, abilities, experience, and expertise of the existing employees (Lemons \& Jones, 2001). Training is equally important for both new and existing employees (Inbal \& Bacharach, 2011). Training brings improvement in employee's knowledge. Employees feel satisfied when the training is continuously exercised by the employer. Employees increase knowledge by learning new things and improving the experience at work (Wood \& Wall, 2002). Training helps employers to achieve organizational goals and keeping employees attached to their jobs. An organization that has an extensive training program for all levels of managers and employees throughout the year. Its employees are fully groomed to perform their jobs and they easily understand what the organization expects from them. They deliver to the organization according to its expectations (Meyer \& Herscovitch, 2001).

Compensation can be defined as the outcome of services, employees receive in the form of wages, salary, and other monetary rewards from the employer in return. By which they satisfy the needs and wants of their entire family. Employees contribute well to their jobs who remain happy at work. Satisfied employees help an organization to achieve goals and improve performance (Luthans \& Sommer, 1999). Compensation is determined in the employment contract when an employee accepts a job offer by reading all the terms and conditions which are written therein. Payments are made on the work done by the employee for the organization. Attractive pay and packages keep employees committed to their jobs (Meyer \& Herscovitch, 2001).

Performance Appraisal can be defined as the process of evaluating the performance of an employee concerning assignments given by the management of the organization (Dole et al., 2001). Performance appraisal is the process of assessing the work performance of an employee within the organization as per given task to allocate rating numbers which will help management to increase salary or rise grade or status within the organization (Wood \& Wall, 2002). An organization effectively achieves its goals by identifying, evaluating, and developing the work performance of its employees. Employees remain happy with the organization when it achieves desired goals and simultaneously contribute to employees in terms of rising pay, packages, and grades. Nothing can keep employees delighted except monetary benefits, which is the primary factor that makes them happy at work, and secondary factors are appreciation, proper support, career guidance, and planning (Sun \& Law, 2007).

\section{Employee turnover intentions}

Employee turnover intentions are described in a way that when an employee makes an intention to leave the present job and search for a new job in the market that pays more to an employee as compared to a previous job (Riley, 2006). Individuals make the intention to leave the organization when they experience various anxieties and stresses related to the work environment, poor support, and lack of career growth, professional justice, the disparity in inputs and outcomes of the job (Samad, 2006). Especially employee turnover intentions are formed with the time spent in the organization (Mahesar, 2015). Employees make perceptions to look for better alternatives available in the market (Rizwan et al., 2013). Previous research conducted on the topic of employee turnover intentions revealed that employee turnover intentions are the most important predictors of actual employee turnover (Griffeth et al., 2000). 


\section{Theoretical framework and Hypotheses}

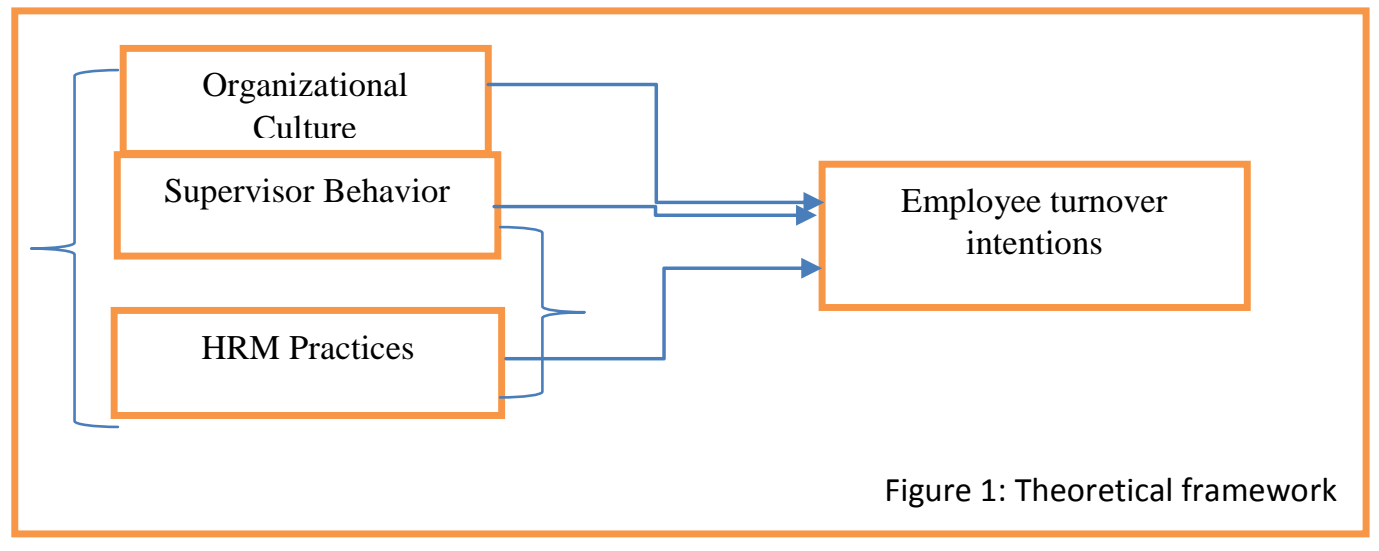

Hypotheses

$\mathrm{H} 1=$ Organizational culture is negatively related to employee turnover intentions.

$\mathrm{H} 2=$ Supervisor behavior is positively related to employee turnover intentions.

$\mathrm{H} 3=\mathrm{HRM}$ practices are positively related to employee turnover intentions.

$\mathrm{H} 4=$ Organizational culture is positively related to HRM practices.

$\mathrm{H} 5=$ Supervisor behavior is positively related to HRM practices.

\section{Research design}

Research design is the systematic, clear, and well-organized procedure by which the data can be collected through primary or secondary means and analyzed by SPSS. Research design helps researchers to plan for data collection, measurement, and analysis and effectively achieve all steps which were set out. Research design helps researchers to know the research activities in advance that will be carried out efficiently and effectively within appropriate time and resources and it helps the researcher to write a hypothesis and test them accordingly (Myers, 2009).

Methodology: This study is cross-sectional and quantitative. Data were collected by close-ended questionnaire based on a seven-point Likert-type scale, containing 27 question items related to 4 variables i-e, organizational culture, supervisor behavior, HRM practices, and employee turnover intentions. Data were analyzed by SPSS and SEM smart PLS. Exploratory and descriptive analysis was done by SPSS and the Model was tested by SEM smart PLS.

Population: Holistic group of people who have shown interest in the research study to supply input and based on that results can be generalized is considered as population (Polit \& Hungler, 1999). The target population for this study was employees of the NGOs sector from Sindh, Pakistan.

Sample and sample size: Sample is the subset of the entire population that is drawn from the population to represent it as a whole (Wood \& Haber, 1998). The sample size for this study was 121 employees of the NGOs sector from Sindh, Pakistan.

Measurement: A questionnaire survey method was used for data collection based on a seven-point Likert-type scale. It was distributed among the target population of the study. There were four parts of the questionnaire related to organizational culture, supervisor behavior, HRM practices, and employee turnover intentions. Organizational culture was measured by 08 question items, supervisor behavior was measured by 04 question items, HRM practices were measured by 10 question items, and employee turnover intentions were measured by 05 question items. Organizational culture items were taken from (Denison, 1990). Supervisor behavior items were taken from (Churchill, Ford, \& Walker, 1974). Employee turnover intentions items were taken from (Cammann et al., 1979; Mathieu \& Zajac, 1990; Griffeth et al., 2000; Lambert et al., 2001; Chew et al., 2005; Yu et al., 2005). Items were measured on seven points Likert-type scale number 1 showing strongly agree and number 7 showing strongly disagree.

\section{Results and discussions}

By descriptive analysis mean was determined for 27 question items. The threshold value for significant mean value is 3.5 at which items were considered fit for further analysis. All items were found fit and significant with above or equal given threshold value of mean except item number 3 of employee turnover intentions, whose mean value declined from its threshold value. Thus it was removed from further analysis. By exploratory analysis corrected item-total correlation was 
determined for 27 question items. The threshold value for significant corrected item-total correlation value is 0.19 (Kehoe, 1995, Ebel \& Frisbie, 1986; Ray, 1982). All items were found fit and significant with above or equal given threshold value except item number 3 of employee turnover intentions, which was measured with a negative value of corrected item-total correlation. Thus it was removed from further analysis and all other items were considered fit for further analysis.

\section{Table 1: Reliability of the instrument}

\begin{tabular}{lll}
\hline Variables & Cronbach's Alpha Value \\
\hline Organizational Culture (OC) & 08 items & 0.880 \\
Supervisor behavior (SB) & 04 items & 0.911 \\
HRM practices (HRMP) $\quad$ 10 items & 0.930 \\
Employee turnover intentions (ETI) 05 items & 0.784 \\
Aggregate reliability (Total items 27$)$ & 0.713 \\
\hline
\end{tabular}

180 questionnaires were distributed among employees of the NGOs sector, out of which 121 questionnaires were considered fit for data analysis and interpretation. Data analyzed through SPSS and Smart PLS. Descriptive and exploratory analyses were done through SPSS and the model was tested by SEM Smart PLS.

The demographic information of the participants is given below in the following table.

Table 2: Demographic information of the participants

\begin{tabular}{llll}
\hline Demographics & Categories & Frequencies & Percentage \\
\hline Gender & Male & 98 & 81 \\
& Female & 23 & 19 \\
Marital status & Married & 71 & 58.7 \\
Age & Single & 50 & 41.3 \\
& $20-29$ & 39 & 32.23 \\
& $30-39$ & 62 & 51.24 \\
Education & $40-49$ & 18 & 14.9 \\
& 50 or above & 02 & 1.7 \\
& Below Bachelor & 01 & 0.83 \\
Experience & Bachelor & 42 & 34.7 \\
& Masters & 69 & 57 \\
& M.Phil./PhD & 09 & 7.4 \\
& Less than 1 Year & 10 & 8.3 \\
& 2-10 years & 82 & 67.8 \\
& $11-20$ years & 25 & 20.7 \\
& $21-30$ years & 02 & 1.7 \\
\hline
\end{tabular}

Male employees were more than female employees with a percentage of 81 out of 100 . Married employees were more than single employees with a percentage of 58.7 out of 100 . The majority of the employees were between the age group of 30-39 years with a percentage of 51.24 out of 100. Most of the employees were master's degree holders with a percentage of 57 out of 100 . The majority of the employees were between the experiences of 2-10 years with a percentage of 67.8 out of 100 who had participated in filling out the questionnaire survey.

Table 3: Factor loading

\begin{tabular}{lll}
\hline Variable & Item & Loading \\
\hline Organizational culture & OC1 & 0.8225 \\
& OC2 & 0.782 \\
OC3 & 0.7708 \\
OC4 & 0.8557 \\
OC5 & 0.7818 \\
OC6 & 0.8529 \\
OC7 & 0.6965 \\
HRM practices & OC8 & 0.7978 \\
& HRMP1 & 0.891 \\
HRMP2 & 0.7755 \\
HRMP3 & 0.8689 \\
HRMP4 & 0.8673 \\
HRMP5 & 0.8735
\end{tabular}




\begin{tabular}{lll} 
& HRMP6 & 0.663 \\
& HRMP7 & 0.8503 \\
HRMP8 & 0.8223 \\
HRMP9 & 0.896 \\
Supervisor behavior & HRMP10 & 0.8503 \\
& SB1 & 0.8645 \\
SB2 & 0.8756 \\
Employee turnover Intentions & SB3 & 0.9071 \\
& SB4 & 0.8781 \\
& ETI1 & 0.9742 \\
& ETI2 & 0.9283 \\
ETI4 & 0.9514 \\
\hline
\end{tabular}

This table shows the factor loading of all items measuring a given construct, where items were loaded in their construct. Literature suggested that the loading value should be greater than 0.7 (Hair et al., 2010). Thus all of the items were loaded with more than significant threshold loading value as it was suggested by literature except HRM practices item 6 and employee turnover intentions item 5 which were loaded a little weaker but both were considered because both were very close to the significant loading values. Factor loading is also known as item variable correlation.

Table 4: Average Variance Extracted, Composite Reliability, R Square and Cronbach's Alpha

\begin{tabular}{lllll}
\hline Variable & AVE & $\begin{array}{l}\text { Composite } \\
\text { Reliability }\end{array}$ & R Square & $\begin{array}{l}\text { Cronbach } \\
\text { Alpha }\end{array}$ \\
\hline OC & 0.6343 & 0.9326 & 0.0000 & 0.9170 \\
HRMP & 0.7030 & 0.9592 & 0.6983 & 0.9522 \\
SB & 0.7770 & 0.9330 & 0.0000 & 0.9048 \\
ETI & 0.7924 & 0.9374 & 0.3784 & 0.9092 \\
\hline
\end{tabular}

This table shows Average Variance Extracted (AVE), R square, Composite reliability, and Cronbach's alpha measured for each of the constructs of the study. Literature suggested that the AVE value should be greater than 0.5 (Fornell \& Larcker, 1981). Composite reliability and Cronbach's Alpha values should be greater than 0.7 (Nunally, 1978). R square was used to find out how much variability is described by independent variables (Hair et al., 2006).

Table 5: Convergent and discriminant validity (Latent variables)

\begin{tabular}{lllll}
\hline & OC & HRMP & SB & ETI \\
\hline OC & $\mathbf{0 . 8 9 0 1 6 9}$ & 000 & 000 & 000 \\
HRMP & -1.4958 & $\mathbf{0 . 8 3 8 4 5 1}$ & 000 & 000 \\
SB & 0.2474 & 0.5419 & $\mathbf{0 . 7 9 6 4 3}$ & 000 \\
ETI & 03865 & -0.1184 & 0 & $\mathbf{0 . 8 8 1 4 7 6}$ \\
\hline
\end{tabular}

This table illustrated that all the constructs had higher convergence of measures on their own proposed construct than on the unintended constructs, which showed that the constructs were correctly operationalized and relatively distinct (Chin et al., 2002).

Table 6: Total Effects Model

\begin{tabular}{llll}
\hline Total Effects & Beta & Standard Error $($ SE) & T-Statistics \\
\hline OC->ETI & 0.1881 & 0.1555 & 1.2103 \\
HRMP->ETI & 0.4464 & 0.2031 & 2.1974 \\
SB->ETI & 0.4193 & 0.1437 & 2.918 \\
OC->HRMP & 0.6066 & 0.1088 & 5.5768 \\
SB->HRMP & 0.2952 & 0.1108 & 2.6639 \\
\hline
\end{tabular}

This table displayed the structural model and the result of five hypotheses that had mentioned in it.

$\mathrm{H} 1=$ Tested the relationship of organizational culture with employee turnover intentions, which was found insignificant and negative between both variables. Thus it was rejected on the ground that lower the t-statistics value from 1.96, which was considered to be the significant threshold value at which any hypothesis accepted.

$\mathrm{H} 2=$ Tested the relationship of supervisor behavior with employee turnover intentions, which was found significant and positive between both variables. Thus it was accepted on the ground that higher the t-statistics value from 1.96, which was considered to be the significant threshold value at which any hypothesis accepted. 
$\mathrm{H} 3=$ Tested the relationship of HRM practices with employee turnover intentions, which was found significant and positive between both variables. Thus it was accepted on the ground that higher the tstatistics value from 1.96, which was considered to be the significant threshold value at which any hypothesis accepted.

$\mathrm{H} 4=$ Tested the relationship of organizational culture with HRM practices, which was found significant and positive between both variables. Thus it was accepted on the ground that higher the tstatistics value from 1.96, which was considered to be the significant threshold value at which any hypothesis accepted.

H5= Tested the relationship of supervisor behavior with HRM practices, which was found significant and positive between both variables. Thus it was accepted on the ground that higher the t-statistics value from 1.96, which was considered to be the significant threshold value at which any hypothesis accepted.

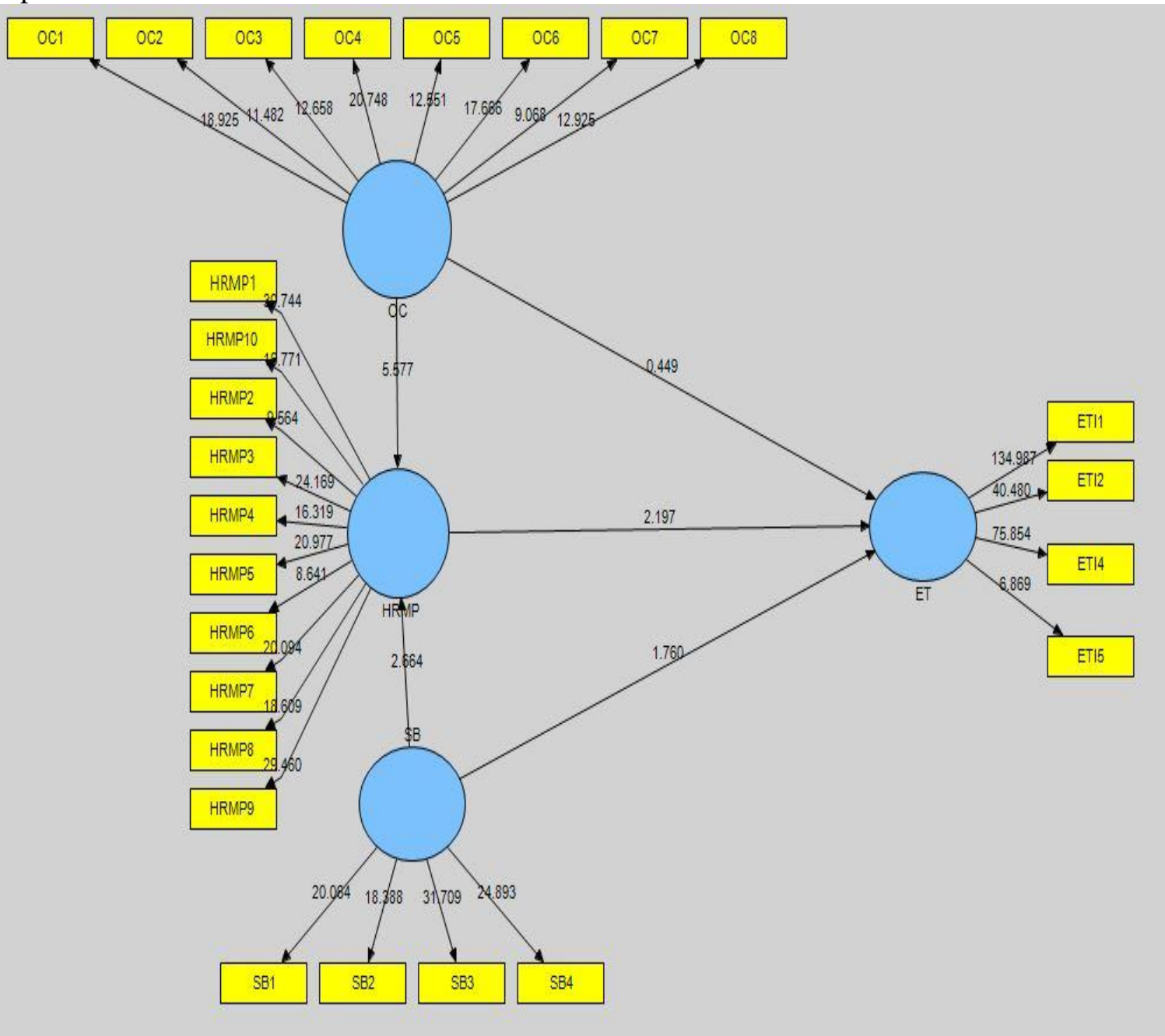

\section{Conclusion}

Employee turnover intentions are generally defined as an employee keeps ideas in mind to leave the current organization and looks for another alternate opportunity in the market that pays equal or more than the current organization (Mobley et al., 1979). Employees experience a variety of problems at a current organization related to organizational culture, poor support of supervisors, the disparity in performance evaluation, lack of career growth and future opportunities and in the aftermath they make intentions to leave the present job and look for another job that pays better than the existing organization (Rizwan et al., 2013). The consequence of employee turnover intentions will be the actual employee turnover, it will be realized when they leave the organization in quest of better opportunity (Mahesar, 2015).

Employees make stay decisions when there is the existence of proper support and guidance found by employees, a good organizational culture based on the belief that there must be love, care, friendship, communication, and cooperation among employees of the organization, employees remain 
happy when they paid handsomely at work, receive rewards and awards timely, receive training on the assignment of a new task (Ashiq et al., 2012). Employee turnover intentions are formed with time spend in the organization, employee learn a lot during the period of the job (Mahesar, 2015).

Employee turnover intentions in the NGOs sector of Sindh, Pakistan were experienced mostly due to supervisor behavior and HRM practices, which were the main causes of employee turnover intentions that will be realized in the form of actual employee turnover. Employee turnover was considered as the greatest loss of the organization when its employee is frequently leaving jobs after getting groomed to play a meaningful role for any organization. Leaving employees were trained fully by the previous organization when an organization needs their valued services for which it had developed their skills and abilities, they made intentions to leave due to a variety of reasons related to supervisor behavior and HRP practices. Since they were happy with the context of organizational culture, which was predicted as a cause of employee turnover intentions. NGOs-type organizations hire supervisors and employees for project-based assignments. Since their services remain for the organizations for short durations. Thus NGOs type organizations focus on supervisor's behavior and HRM practices which are perceived variables of employee turnover intentions in such organizations.

\section{Theoretical Implications}

This study investigated the impact of organizational culture, supervisor behavior, and HRM practices on the employee turnover intentions of the NGOs sector in Sindh, Pakistan. The theoretical implications of this study are that this research will contribute to the extant literature on organizational culture, supervisor behavior, and HRM practices over employee turnover intentions of NGOs sector in general and NGOs sector in Sindh Pakistan in particular. Moreover, referring to the empirical finding of current research NGOs in Sindh might be able to reduce employee turnover. Similarly, the policymakers of NGOs in Sindh might be able to devise different policies regarding supervisor behaviors, employee turnover intentions, and contemporary HRM practices, and so on.

\section{Limitations and Future Research Directions.}

The limitation of current research is that this study focused on NGOs in Sindh only. A study at the country level NGOs sector will further help to understand organizational culture, supervisor behavior, HRM practices, and employee turnover intentions to help policymakers in the social development sector. Moreover, in the future, a comparative study between two or more than two developing countries can further depict a broader picture of issues related to organizational culture, supervisor behavior, and HRM practices over the employee intentions in the social development sector.

\section{References}

Abagelan, S., \& Tullu, D. T. (2020). Employee Turnover in Non-Profit Organizations in Jimma Prefecture, Ethiopia.

Ahmed, Z., Othman, N. B., \& Yean, T. F. Impact of Human Resource Management Practices on Employee Retention: A Study of Public Healthcare Sector of Pakistan. IOSR Journal of Business and Management (IOSR-JBM) e-ISSN: 2278-487X, p-ISSN: 2319-7668. Volume 22, Issue 7. Ser. V (July 2020), PP 09-15 www.iosrjournals.org

Amin, M. B., \& Rubel, M. R. B. (2020). Human resource management practices and employee knowledge sharing behavior: Mediating role of knowledge sharing intention. Asian Journal of Empirical Research, 10(5), 150-164.

Chen, Z. (2001). "Further investigation of the outcomes of loyalty to supervisor: job satisfaction and intention to stay", Journal of Managerial Psychology, Vol. 16, pp. 650-60.

Da Silva, J., Riana, I. G., \& Soares, A. D. C. (2020). The Effect of Human Resources Management Practices on Innovation and Employee Performance (Study Conducted at NGOs Members of FONGTIL) Dili. International Journal of Multicultural and Multireligious Understanding, 7(9), 322-330.

Dole et al. (2001). The impact of various factors on the Personality, Organization Contentment and Turnover Intention Of Organizational Accounts, Managerial Auditing Journal, 16/4, 234-245.

Gilbreath, B. (2005). Supervisor practices instrument [Measurement instrument]. Hasan School of Business, Colorado State University-Pueblo, Pueblo, CO.

Griffeth et al. (2000). "A meta-analysis of antecedents and correlates of employee turnover: update, moderator tests and research implications for the next millennium", Journal of Management, Vol. 26, pp. 463-88.

Hofstede, G. (2011). Dimensionalizing Cultures: The Hofstede Model in Context. Online Readings in Psychology and Culture, Unit 2. Retrieved from http://scholarworks.gvsu.edu/orpc/vol2/ iss1/8. 
Hom, P. W. et al. (2012). Reviewing employee turnover: focusing on proximal withdrawal states and an expanded criterion. Psychological Bulletin, 138(5), 831.

Hoobler, J. M., \& Brass, D. J. (2006). Abusive supervision and family undermining as displaced aggression. Journal of Applied Psychology, 91, 1125-1133.

House, R. J., Hanges, P. J., Javidan, M., Dorfman, P. W. \& Gupta, V. (Eds.). (2004). Culture, leadership, and organizations: The GLOBE study of 62 societies. Thousand Oaks, CA: Sage.

Inbal Nahum-Shani, P. A., \& Bacharach, S. B. (2011). Social Support and Employee Well-Being: The Conditioning Effect of Perceived Patterns of Supportive Exchange. Journal of Health and Social Behavior, Vol. 52, No. 1, 123-139.

Inglehart, R. (1997). Modernization and postmodernization: Cultural, economic, and political change in 43 societies. Princeton, NJ: Princeton University Press.

Jansson, M., \& Linton, S. J. (2006). Psychosocial work stressors in the development and maintenance of insomnia: A prospective study. Journal of Occupational Health Psychology, 11, 241-248.

Jhatial et al. (2012). Antecedents and Consequences of Employee Turnover: Empirical Evidence from Pakistan. British Journal of Economics, Management \& Trade, Vol. 2(4), pp. 279-295, 2012.

Karimi, L., Karimi, H., \& Nouri, A. (2011). Predicting employees' well-being using work-family conflict and job strain models. Stress \& Health, 27, 111-122.

Lemons, M. A., \& Jones, C. A. (2001). Procedural justice in promotion decisions: using perceptions of fairness to build employee commitment. Journal of Managerial Psychology, Vol.16, No.4, 268280.

Luthans, B. C., \& Sommer, S. M. (1999). The impact of downsizing on workplace attitudes differing reactions of managers and staff in a health care organization. Group \& Organization Management, 24(1), 46-70).

Mahesar, H. (2015). The impact of HRM bundles and Organizational Commitment on Managers turnover intentions. University of Bedfordshire $\mathrm{PhD}$-e-thesis.

Meyer, J. P. \& Herscovitch, L. (2001). "Commitment in the workplace: toward a general model", Human Resource Management Review, Vol. 11, pp. 299-326.

Mobley, W. H., Griffeth, R. W., Hand, H. H., \& Meglino, B. M. (1979). Review and conceptual analysis of the employee turnover process. Psychological Bulletin, 86, 493-522.

Price, J. L. (2001). Reflections on the determinants of voluntary turnover. International Journal of Manpower, Vol. 22, No. 7, pp.600-624.

Price, J.L. and Mueller N (1986). The study of turnover.Ames, Iowa State University.

Riley, D. (2006). Turnover Intentions: The Mediation Effects of Job Satisfaction, Affective Commitment and Continuance Commitment. University of Waikato.

Rizwan et al. (2013) Impact of Psychological Factors on Employee Turnover Intentions, International Journal of Research in Commerce, Economics and Management, 3(3), 63- 69.

Rizwan et al. (2013). Variables that have an Impact on Employee Satisfaction And Turnover Intention, International Journal of Research in Commerce, Economics and Management, 3(3), 131-138.

Sabuhari, R., Sudiro, A., Irawanto, D., \& Rahayu, M. (2020). The effects of human resource flexibility, employee competency, organizational culture adaptation, and job satisfaction on employee performance. Management Science Letters, 10(8), 1775-1786.

Salleh, A. M. M., Omar, K., Aburumman, O. J., Mat, N. H. N., \& Almhairat, M. A. (2020). The impact of career planning and career satisfaction on employee turnover intention. Entrepreneurship and Sustainability Issues, 8(1), 218.

Samad, S. (2006). The Contribution of Demographic Variables: Job Characteristics and Job Satisfaction on Turnover Intentions. Journal of International Management Studies.

Sardar, M., \& Mahdi, T. (2020). Impact of Organizational Culture on Innovative Work Behavior. Black Sea Journal of Management and Marketing, 1(2), 11-20. DOI: 10.47299/bsjmm.v1i2. 57

Sun, L. Y., Aryee, S. \& Law, K. (2007). 'High-performance human resource management practices, citizenship behavior and organizational performance, a relational perspective'. Academy of Management Journal, 50, 558-77.

Vandenberg \& Nelson (1999). Disaggregating the motives underlying turnover intentions: When do intentions predict turnover behavior? Human relations 52 (10): 1313-1336.

Wood, S. J., and Wall, T. D. (2002). 'Human resource management and business performance. In Warr, P. B. (Ed.), Psychology at work, $5^{\text {th }}$ edition. London: Penguin, 351-74. 